\section{Extensão universitária participativa para a sustentabilidade: artesanato identitário da Associação Mães de Nazaré de Chapecó}

\author{
Bernardete Bregolin Cerutti \\ Coordenadora do Núcleo de Educação \\ Continuada da Universidade do Vale do \\ Taquari, Brasil. \\ bcerutti@univates.br
}

\author{
Graciela Alves de Borba Novakowsk \\ gracielan@unochapeco.edu.br \\ (iD) orcid.org/0000-0002-0563-2109 \\ Andréia Casagrande Begnini \\ andréiabegnini@gmail.com \\ (iD) orcid.org/0000-0002-7971-4561 \\ Universidade Comunitária da Região \\ de Chapecó, Brasil.
}

RECEPCIÓN: 24/06/19

ACEPTACIÓN FINAL: 01/08/19

\section{Resumo}

Este trabalho relata a experiência do projeto de pesquisa e extensão universitária coordenada pela Incubadora Tecnológica de Cooperativas Populares (ITCP) da Universidade Comunitária da Região de Chapecó (Unochapecó) junto à associação de artesanato Mães de Nazaré de Chapecó. Como procedimento metodológico, foi utilizada a pesquisa participante, onde pesquisados e pesquisadores puderam construir e desenvolver o projeto conjuntamente. Foi definido no decorrer do processo como objetivo orientar as artesãs para a produção de artesanato que identifique a região e estabeleça uma relação direta com os novos mercados, as tendências e demandas que podem ser exploradas de forma significativa - turismo, eventos, gastronomia, design e decoração, entre outras. Trata-se de um tema que envolve tramas, identidades e políticas na construção do território.Como resultado, ao término do projeto, a associação ampliou o número de participantes e inseriu em sua prática conceitos de autogestão que possibilitou o aumento da produção, a inclusão social e o reconhecimento do produto no mercado local.

Palavras-chave: artesanato, associação Mães De Nazaré, extensão, autogestão, cultura.
Participatory University Extension for Sustainability: Identity Handicraft of the Mães de Nazaré Association of Chapecó

\section{Abstract}

This work reports the experience of the research project and university extension coordinated by the Technological Incubator of Popular Cooperatives (ITCP) of the Community University of the Region of Chapecó (Unochapecó) together with the craft association Mães de Nazaré de Chapecó. As a methodological procedure, participant research was used, in which researchers and researchers were able to construct and develop the project together. During the course of the process, the goal was to guide the artisans to produce handicrafts that identify the region and establish a direct relationship with the new markets, the trends and demands that can be significantly explored - tourism, events, gastronomy, design and decoration, among others - It is a theme that involves plots, identities and policies in the construction of the territory. As a result, at the end of the project, the association increased the number of participants and inserted in its practice concepts of self-management that enabled increased production, social inclusion and recognition of the product in the local market.

Keywords: crafts, Association Mães De Nazaré, extension, self-management, culture.
Cultura(s) en clave de extensión universitaria / Intervenciones 다(1)(2)
Extensión universitaria participativa para la sustentabilidad: artesanía identitaria de la Asociación Madres de Nazaret de Chapecó

\section{Resumen}

Este trabajo relata la experiencia del proyecto de investigación y extensión universitaria coordinado por la Incubadora Tecnológica de Cooperativas Populares (ITCP) de la Universidad Comunitaria de la Región de Chapecó (Unochapecó) junto a la asociación de artesanías Madres de Nazaret de Chapecó. Como procedimiento metodológico, se utilizó la investigación participante, donde investigados e investigadores pudieron construir y desarrollar el proyecto conjuntamente. Se definió como objetivo en el transcurso del proceso orientar a las artesanas para la producción de artesanía que identifique la región y establezca una relación directa con los nuevos mercados, las tendencias y demandas que pueden ser explotadas de forma significativa -turismo, eventos, gastronomía, diseño y decoración, entre otras-. Se trata de un tema que involucra tramas, identidades y políticas en la construcción del territorio. Como resultado, al término del proyecto, la asociación amplió el número de participantes e introdujo en su práctica conceptos de autogestión que posibilitaron el aumento de la producción, la inclusión social y el reconocimiento del producto en el mercado local.

Palabras clave: artesanía, Asociación Madres De Nazaret, extensión, autogestión, cultura. 


\section{Introdução}

O artesanato é um fator significativo para o desenvolvimento local, seja em grupos formalizados ou não, a produção artesanal é expressão cultural e gera renda. O local de consumo do artesanato, em sua maioria, pode ser definido por galerias, museus, mercados ou feiras. Verifica-se que os primeiros elementos artesanais foram do período neolítico, neste, o processo dava-se em torno da transformação de matérias-primas como fibra, pedras em utilidades para auxiliar no dia-a-dia.

O ofício do artesão tornou-se uma profissão passada entre as gerações na família, primeiramente com uma produção apenas para o consumo próprio e posteriormente para complementação da renda. Pensar a respeito da importância do artesanato no município de Chapecó, localizado no oeste de Santa Catarina, é trazer à tona uma crescente necessidade de ampliar as expressões culturais que narrem a história de seus imigrantes. O conceito de "produção artesanal" está ligado ao fazer tendo as mãos como principal ferramenta, utilizando máquinas apenas como auxílio (Lima, 2003). Diferentemente da produção industrial, a artesanal é feita em pequena escala e as peças possuem autenticidade.

A extensão universitária apresenta-se como um meio de agregar na formação acadêmica dos estudantes, possibilitando a estes participar de experiências que os aproximem da comunidade e contribuam para o desenvolvimento local. A prática da extensão é importante para o aluno e para o grupo em que ele é inserido. Os estudantes que participam da extensão universitária são oriundos de diversos cursos, como: psicologia, pedagogia, economia, administração, serviço social, entre outros e nas suas inserções são capacitados e acompanhados pelo Programa de Extensão Incubadora Tecnológica de Cooperativas Populares (ITCP), por técnicos e docentes que, a partir das teorias, dos dados e de pesquisas, geram os subsídios importantes para o desenvolvimento das atividades de extensão na comunidade. Boa parte dos projetos que são acompanhados pela extensão universitária chega até a incubadora por procura da própria comunidade, que busca o apoio da equipe (técnicos, docentes e estudantes) para a resolução dos gargalos de seus processos para o desenvolvimento regional.

O estudo que resultou neste artigo diz respeito a um trabalho de pesquisa e extensão realizado pela ITCP no grupo de artesãs Mães de Nazaré. $O$ artigo trata de uma experiência que envolveu toda a equipe da extensão universitária, com ações que contribuíram com a comunidade. Apresenta-se a experiência do grupo e sua contribuição para a aplicação das expressões culturais, bem como o desenvolvimento do projeto com a participação das associadas.

O artesanato nos traz essa premissa da valorização cultural de território, e isso somente ocorre de forma significativa e contundente, quando fazemos referência ao nosso lugar de origem. Sejam os saberes artesanais mais antigos, sejam os que surgem através de novos enredos, somente possuem essa carga simbólica quando retratamos aquilo que nos identifica. Nesse sentido, este trabalho traz o relato de experiência do grupo de artesãs Mães de Nazaré de Chapecó, em busca de fomentar o artesanato cultural de identidade da região e sua contribuição para o desenvolvimento regional nos segmentos cultural, econômico e social.

Este se encontra dividido em quatro seções essenciais: introdução, que apresenta o problema de pesquisa e objetivo do estudo; procedimentos metodológicos e fundamentação teórica; relato da experiência da Associação Mães de Nazaré e os resultados; considerações finais. 


\section{Procedimentos metodológicos}

De acordo com Freire (1986), a pesquisa visa contribuir com a formação do caráter crítico e transformador. Sendo assim, o pesquisado deixa de ser um objeto de pesquisa e torna-se sujeito junto ao pesquisador. A pesquisa de natureza aplicada propõe-se a apresentar alternativas para a solução de problemas concretos. Através de uma abordagem participante no contexto da Associação Mães de Nazaré, tem-se a figura das artesãs, dos alunos de extensão e técnicos da ITCP. A pesquisa participante é definida como um processo no qual os pesquisados participam da análise da sua realidade visando a transformação social e benefícios para os participantes. Lakatos e Marconi (2001) a definem como um tipo de pesquisa que não possui um planejamento ou um projeto anterior à prática, sendo que só será construído junto aos participantes, definindo objetivos, cronograma e forma de ação.

De acordo com Brandão (1981), a pesquisa participante tem um enfoque de investigação social, buscando a participação da comunidade na análise de sua realidade. Trata-se de uma atividade de educação de investigação e ação social visando promover benefícios para os participantes.

A pesquisa foi realizada junto à Associação Mães de Nazaré situada no distrito de Marechal Bormann, município de Chapecó, Santa Catarina/Brasil, envolvendo 20 associadas com idade média de 32 anos que atuam diretamente. As reuniões ocorrem informalmente há 15 anos, objetivando o aprendizado de trabalhos manuais e o aproveitamento de resíduos têxteis provenientes de indústrias de confecções do município.

O processo de organização das associações inicia, em sua maior parte, por elementos de solidariedade e partilha. De modo geral, as associações possuem um grau de autonomia e buscam formas de viabilizar a financeira. $O$ associativismo ligado ao desenvolvimento de atividades produtivas ganhou espaço e visibilidade nos últimos anos no Brasil. Foram mapeados, entre 2009 e 2013, 11.823 empreendimentos econômicos solidários constituídos na forma de associativismo, o que representa $60 \%$ dos empreendimentos identificados no País (IPEA, 2016).

Considera-se o associativismo produtivo como uma forma de organização que difere das estruturas produtivas predominantes, sua base na relação é a identidade com o grupo associado e com a atividade desenvolvida, e não a relação capital-trabalho.

Para iniciar o trabalho, a ITCP tratou com as artesãs de três momentos distintos: o primeiro, de sensibilização, visando resgatar a história e motivação da associação - utilizou-se uma roda de conversa com apresentação das artesãs, seguida pela apresentação da incubadora e do objetivo de estarem ali; no segundo momento, foram contextualizadas as situações que, de acordo com o entendimento das artesãs, atrapalham o andamento dos trabalhos internos da associação - foram todas listadas em um cartaz; e no terceiro momento, havendo consciência das situações apontadas, iniciou-se o processo de busca pela superação das dificuldades encontradas. As falas e observações foram registradas pelos pesquisadores. A partir dessa coleta de dados, buscaram-se subsídios para análise e interpretação. 


\section{Identidade cultural e territorial}

Na Universidade Comunitária da Região de Chapecó (Unochapecó), ${ }^{1}$ os programas e projetos de extensão, graduação, pós-graduação e grupos de pesquisas, são guiados pelos pressupostos do compromisso com o desenvolvimento regional sustentável, interação transformadora, mediadora do processo de construção de conhecimentos e responsabilidade social. As ações atendem aos princípios: interação dialógica com os setores sociais, interdisciplinaridade e interprofissionalidade, indissociabilidade do ensino, pesquisa e extensão, impacto na formação do estudante, impacto e transformação social e, metodologias avaliativas.

A Incubadora Tecnológica de Cooperativas Populares (ITCP) da Unochapecó tem objetivo de fortalecer seus empreendimentos e grupos, melhorando as condições de vida de muitos trabalhadores e trabalhadoras da cidade e do campo que se encontravam excluídos do mercado formal de trabalho e dos direitos básicos de cidadania.

Suas ações contribuem e auxiliam na construção de alternativas de geração de trabalho, renda e organização das populações desta região. Criada em 2003, vem executando projetos de captação externa com foco na incubação e assessoria a empreendimentos, cuja gestão se pauta nos princípios da Economia Solidária, como cooperação, solidariedade e autogestão. Desde sua criação, já executou mais de 12 projetos com diversas financiadoras como FINEP, Proninc, Senaes, Banco do Brasil, TetraPak, CNPq, entre outros convênios com entidades e prefeituras da região.

A Universidade, por sua vez, quando responsável pela proposição e execução de um projeto de extensão e intervenção econômica com vistas à geração de trabalho e renda, acaba desenvolvendo de forma plena seus preceitos enquanto universidade. Não apenas por atuar num programa de forte significado social, mas também por que, através dele, poderá estabelecer um diálogo acadêmico privilegiado com a realidade social como um todo e, em particular, com a realidade dos grupos populares no tocante à sua inserção no mundo do trabalho.

Através da atuação da ITCP foi possível o desenvolvimento de atividades de extensão que permitiram um contato permanente dos docentes e alunos das diversas áreas do conhecimento com a realidade indicada e, a partir disto, aperfeiçoar o processo de formação profissional e identificar objetos de pesquisa que, sob os diferentes olhares acadêmico-científicos, podem ser investigados, resultando na produção de novos conhecimentos.

\section{Território e identidade}

A ITCP da Unochapecó é um programa permanente de extensão que tem por finalidade a inserção de atores marginalizados economicamente no sistema formal de economia, a partir da organização para o trabalho, e nas suas comunidades conquistar a cidadania, bem como constituir um novo espaço de produção acadêmica interdisciplinar, tanto no campo do ensino (aperfeiçoamento da formação profissional), quanto no campo da pesquisa e da extensão.

Os conceitos teóricos das principais temáticas e metodologias da ITCP-Unochapecó, são: Desenvolvimento Sustentável, Desenvolvimento Territorial, Economia Solidária, Educação Popular, Pesquisa-Ação e Sistematização. Vale pontuar que neste item não há a preten-

1) Mantida pela FUNDESTE, comprovadamente vem fortalecendo e consolidando sua inserção e compromisso com o processo de desenvolvimento inclusivo da região oeste catarinense, comprometida com o tripé ensino, pesquisa e extensão, sendo que na extensão universitária conta com os programas permanentes de extensão. 
são de realizar profundas discussões teóricas, mas sim, de apresentar, de maneira objetiva, estes conceitos teóricos orientadores das ações da incubadora.

Quanto ao desenvolvimento territorial, (Froehlich e Alves, 2004:67), compreende que se trata de uma nova possibilidade que surge a partir do esgotamento dos modelos tradicionais de crescimento econômico, unido à consciência do uso demasiado dos recursos e à necessidade da construção de sociedades mais justas, "faria parte de um movimento cultural, de âmbito planetário, no sentido de um amplo questionamento sobre a produção, o consumo, a política e os modos de viver predominantes nas últimas décadas". Assim, esse processo de mudança faz com que seja destacada a valorização das especificidades e diferenças culturais e aumente a preocupação com o meio ambiente.

Froehlich e Alves (2004) afirmam que esta preocupação ambiental que estamos presenciando com o trabalho do grupo contesta as possibilidades de criação de espaços locais e rurais que passam a ser construídos socialmente.

Este rebatimento é multiforme e capaz de imprimir, para além das chamadas novas funções não-agrícolas do rural, matizes renovados a categorias derivadas da própria dinâmica social do mundo rural, como a identidade coletiva e a sociabilidade local. As identidades sociais de grupos, quer catalisadas por variáveis territoriais, étnicas ou culturais, podem ser definidas como o resultado de um duplo processo, de afirmação versus distinção, que se vai forjando na base de relações de interdependência e dos círculos sociais que os indivíduos vão estabelecendo entre si nas situações cotidianas de suas vidas (Froehlich e Alves:68).

Neste sentido, os autores compreendem que processos de globalização e de localização/ regionalização não estão indissociados, ou seja,

"Pulverizado por particularismos e singularidades, mas em conexão com o social mais amplo, o lugar recebe determinações externas e as combina às narrativas locais. (...) Se antes as populações dos lugares tinham a sua percepção do espaço social limitado àquele necessário a sua própria reprodução, hoje, o mundo - as evoluções de uma 'ordem' internacional - se coloca também como referência incontornável". (p. 69)

Considerando isso, segundo estes autores Froehlich e Alves (p. 70), não é mais possível pensar o mundo sem admitir que um mesmo espaço seja sempre um espaço plural, onde há diferentes formas de se afiliar ou se identificar com um território. Porém, a "desterritorialização" ou "deslocalização", compreendida pelos autores, não anula o espaço, mas organiza uma forma de concorrência entre espaços locais ou regionais.

As relações entre identidade cultural e territorial permitem estabelecer a interconexão entre a memória individual e a história de uma comunidade, sendo possível recuperar a memória coletiva de um grupo social. A história dos mundos de vida distintos, conforme perspectiva orientada ao ator, proposta por Norman Long $^{2}$, ganha relevância nessa reflexão,

2) Norman Long, a partir da influência da Escola de Wageningem e de estudos etnográficos na África e na América Latina, constrói a Perspectiva Orientada ao Ator, que foi posteriormente enriquecida com os aportes de Jan Douwe van der Ploeg. Esta perspectiva, com base na teoria pós-estruturalista de Anthony Giddens e dos princípios do construtivismo social, possibilita identificar e analisar a visão de desenvolvimento dos diferentes atores nos espaços específicos e os produtos resultantes desse amálgama dentro das arenas sociais, considerando como os diferentes atores na interface, a partir de seus conhecimentos, experiências, recursos, significados e propósitos, influenciam a formulação e a implementação de políticas e projetos de desenvolvimento (Long, 2007). 
na medida em que a história de vida de uma pessoa está ligada à sua memória, e esta possui capacidade de criar e recriar estratégias por meio de suas interações sociais e institucionais.

Assim, a memória coletiva de um grupo é passada de geração em geração e, dessa forma, a identidade cultural de uma determinada comunidade não se perde, sendo sustentada pela memória e pela narrativa. A memória, conforme Scheibe et al. (1985) deve ser entendida como uma construção social feita pela seleção de experiências de vida que possibilitam uma narrativa de como se é e, por que se é assim, e não como uma pura e simples faculdade mental.

Para Simson (2000:63), "memória é a capacidade humana de reter fatos e experiências do passado e transmiti-los às novas gerações, através de diferentes suportes empíricos”. A memória também é seletiva, de acordo com Pollak (1992), uma vez que as pessoas só têm recordações dos momentos aos quais dão determinada importância, que, por algum motivo, ficaram marcados subjetivamente. Além disso, parte das lembranças pode ser herdada dos acontecimentos passados.

A "história que se sabe" é registrada e interessa à medida que evoca uma memória coletiva, seletiva e classificatória (Barros, 1989). Dessa forma, a memória herdada possui relação direta com o sentimento de identidade, tanto individual como coletiva, uma vez que ela é também um fator importante do sentimento de continuidade e de coerência de uma pessoa ou de um grupo no processo de reconstrução identitária. Portanto, o processo que define a identidade cultural decorre do mundo vivido das pessoas, do mundo de vida dos locais, das relações de convivência, provenientes de diferentes espaços físicos e sociais, da disposição de compartilhar lembranças e saberes, em um processo de contínuo reconhecimento e reconstrução (Long, 2007; Halbwachs, 1990).

Nessa perspectiva, o território caracteriza-se como uma identidade coletiva com um número de municípios articulados em termos de expectativas de desenvolvimento, visando à integração econômica e social, ao nível local. Essa abordagem traz consigo aspectos importantes, como a integração de diversas atividades, a valorização coletiva e a negociação das potencialidades das localidades ou das regiões, evidenciando que o território é o resultado de uma ação social (Flores, 2017), que apresenta contradições e exercícios entre o uso econômico e social dos recursos (Etges, 2001). Por isso, a construção de territórios, considerando a diversidade de realidades, exige estratégias que sejam coerentes com o estágio de desenvolvimento de cada região (Tonneau, 2002), pois é um espaço social e real.

Diante disso, é possível afirmar que a territorialidade é também uma relação de afinidade e de alteridade - vive-se com os outros e os limites geográficos são as relações cotidianas que levam à construção ou desconstrução dos territórios (Pecqueur, 2009). O deslocamento das pessoas desarticula as identidades, mas abre também a possibilidade de novas articulações. Assim, a afirmação de identidade está envolta das relações sociais, que estão ligadas aos aspectos culturais expressos nos saberes-locais, e de poder, traduzindo o desejo, bem como as contradições, dos grupos sociais envolvidos. As identidades mobilizam os atores para definir parceiros e adversários, isto é, para assumir posicionamento. Isso evidencia uma relação de poder, porque definir uma identidade significa assumir posição perante os outros, constituindo um processo de inclusão e de exclusão de grupos e atores sociais, resultantes da produção simbólica e discursiva (Flores, 2006).

Entende-se, assim, que o território deve ser considerado um processo de construção social, que só existe a partir da materialidade que lhe é dada por seu uso. Nesse sentido, Etges 
(2005:54) destaca que "Um território traz a marca de gerações que ali viveram e trabalharam; (...) é resultante do tipo de organização social ali criada". Em consequencia"o território não é refúgio, receptáculo passivo (...), recipiente, abrigo ou superfície, que simplesmente acolhe ou acondiciona o que nele está contido" (Brandão, 2013:13). Ao contrário, no território, materializam-se as relações entre indivíduos e grupos sociais (Raffestin, 1993; Santos, 2009).

A análise das representações sociais dos artesãos permite observar como esses atores sociais posicionam-se no espaço ${ }^{3}$ de uma maneira reflexiva, ou seja, as representações são manipuladas para justificar as ações, as ações modificam as representações, e nessa relação entre representações e práticas do espaço e no espaço, em que interferem as diferenças de gênero, tradições e etnias, constroem-se os territórios. São os diversos atores dessas localidades que definirão ou não a articulação interna nas comunidades locais e a natureza de suas relações externas com a sociedade regional, estadual, nacional e global.

Os processos de integração entre diferentes grupos étnicos, decorrentes de migrações, em que os atores têm de transitar e negociar entre múltiplas culturas, caracterizam o hibridismo e fazem surgir as identidades culturais híbridas. Como aponta Hall (2002), as identidades movem-se entre dois eixos: o da tradição, no qual as identidades tentam resgatar a sua essência inata; e, o da tradução, em que existe uma permanente negociação entre velhas e novas identidades, no caso, as identidades híbridas. Assim, o global e o local influenciam-se mutuamente, deslocando as velhas identidades para novas possibilidades de identificação cultural.

Nessa perspectiva, configura-se uma nova articulação entre o global e o local. O local precisa ser percebido, atuando no interior da lógica da globalização, o que pode gerar novas identificações, global e localmente. O progresso de globalização tem influenciado a comercialização de produtos artesanais, tendendo à fragmentação e à mercantilização dos seus valores, fazendo com que ocorra o hibridismo. Essa fusão de elementos tradicionais e modernos, de diferentes tempos, é parte do processo histórico e da luta de diferentes grupos excluídos socialmente do processo de construção de suas identidades locais e regionais.

As associações de artesanato promovem, a junção desses elementos reflete-se nas formas dos objetos, na preferência de cores, no uso de materiais e insumos, nas técnicas de produção típicas da região, no uso de elementos simbólicos que fazem referência às origens de seus produtores ou de seus antepassados. Assim, a inspiração para a prática do trabalho artesanal provém da história do artesão e da conjugação dos fatores étnicos, culturais, econômicos, sociais e ambientais que configuram seu cotidiano.

Entre a tradição e a modernidade, o artesanato e o artesão atravessam um profundo processo de transformação, uma vez que se encontram inseridos num mercado que se reinventa constantemente. Entretanto, a prática cultural continua existindo porque sua informação cultural foi passada de uma geração a outra. Assim, o passado inspira as manifestações tradicionais, norteando o presente e o futuro como fonte de identidade.

3) O espaço é sempre uma conjuntura histórica e social que recebe sentido das formas herdadas de uma outra funcionalidade, reconstruída sob uma nova organização. É a coexistência do passado e do presente ou de um passado reconstruído no presente. Assim, o espaço se reproduz na medida das necessidades sociais, econômicas, políticas e culturais influenciando a evolução de outras estruturas sociais, resultando em diferentes inserções, carregando heranças e possibilidades (Santos, 1982). 


\section{Associação Mães de Nazaré e resultados}

Na construção da Economia Solidária e autogestão como estratégia de desenvolvimento, na relação ensino, pesquisa e extensão se constituem num tripé indissociável, sendo o trabalho o processo mediador da construção do conhecimento, conforme Adams (2014), Gaiger (1996) entre outros.

No processo de incubação não poderia ser diferente, essa integração e integralização também acontece, pois o processo de intervenção na realidade se estrutura nas bases da Educação Popular, em que o processo reflexivo/formativo parte da realidade dos sujeitos envolvidos ao se conhecerem mutuamente, na reflexão sobre a realidade imediata vivida $e$ a ampliação da construção da visão do seu entorno. Esse caminho percorrido não acontece sem pesquisa (participativa, pesquisa-ação) sem a troca de conhecimentos e construção de novos conhecimentos.

A integração do ensino, pesquisa e extensão junto aos sujeitos, com a participação direta de professores, técnicos e acadêmicos de suas respectivas áreas de conhecimento, permite a relação (multi e transdisciplinaridade) proporcionada pela vivência das realidade de atuação.

Como fruto dessa concepção de construção de conhecimento (indissociação do tripé) a ITCP-Unochapecó já produziu mais 40 artigos científicos (iniciação), publicados e socializados em diversos eventos internos da instituição, eventos regionais, nacionais e internacionais, das diversas áreas do conhecimento. Também já contabilizou aproximadamente um Trabalho de Conclusão de Curso (TCC), por ano. Além de aproximadamente 10 (dez) trabaIhos de stricto sensu, entre teses e dissertações. No campo do material didático também já foram produzidas 8 (oito) cartilhas didáticas sobre temas de formação.

Encontram-se na base desse trabalho acadêmico os cursos como Agronomia, Ciências Econômicas, Administração, Ciências Contábeis, Direito, Psicologia, Serviço Social, Nutrição, Gastronomia, Comunicação Social, dentre outros em processo de aproximação junto ao programa de extensão ITCP. Importante destacar o envolvimento dos Núcleos de Pesquisa, dentre os quais o Núcleo de Desenvolvimento Regional e o Núcleo de Trabalho, Organizações Sociais e Políticas Públicas.

O desenvolvimento do Programa de Extensão ITCP com os diversos cursos já citados revela o esforço institucional de cumprir os princípios e diretrizes estabelecidas no PDI (Plano de Desenvolvimento Institucional) aprovado através da resolução ${ }^{\circ} 098$ de 2005, pelo CONSUN (Conselho Universitário). Dentre os princípios podemos destacar a "Indissociabilidade do Ensino, Pesquisa e Extensão, a Pluralidade, a Autonomia, a Formação cidadã e o Compromisso com o desenvolvimento regional sustentável", que apresentam uma relação mais direta com a ITCP.

Dentre as diretrizes institucionais, o PDI busca:

"Reafirmar e consolidar o perfil institucional acadêmico intensificando a garantia da universalização do saber; a formação humanística, técnica, ética, estética e social e a multidisciplinaridade, interdisciplinaridade e transdisciplinaridade nos currículos de formação profissional”. (Unochapecó, 2005:s/n)

Busca ainda "Articular o processo de formação de profissionais com os contextos local, regional, nacional e global tendo em vista a produção e difusão do conhecimento", capaz de "Estimular o debate epistemológico e didático-pedagógico em torno das mudanças nas 
formas de conceber e produzir o conhecimento", para o qual se faz necessário "Consolidar as políticas de pesquisa e extensão" e assim, "Constituir-se em centro de referência acadêmica para questões regionais, respondendo aos desafios da sustentabilidade" (Unochapecó, 2005).

Neste contexto, o grupo de Mães Maria de Nazaré, localizado no distrito de Marechal Bormann, município de Chapecó, Oeste de Santa Catarina, é constituído por aproximadamente 20 mulheres. $O$ grupo reúne-se informalmente há 15 anos, e no decorrer desse tempo vem trabalhando na confecção de produtos artesanais com a matéria-prima totalmente reciclada, ou seja, resíduos têxteis provenientes de indústrias de confecção do município e região. Atualmente os encontros ocorrem semanalmente, tendo como local uma sala cedida por uma associada residente naquela localidade.

Após o primeiro contato com a ITCP, as associadas fizeram um resgate histórico do grupo e indicaram como vontade o registro formal deste. Esse processo foi realizado em 2010, com a assessoria da incubadora. $O$ fato de registar o grupo como uma associação indica uma segunda situação apresentada pelas artesãs: a necessidade de fomentar o artesanato através do desenvolvimento de produtos aptos a atenderem o mercado consumidor, promovendo assim a autonomia e uma melhoria na qualidade de vida dos envolvidos com a renda.

A premissa foi organizar e orientar as artesãs a produzirem um artesanato que identifique a região, estabelecendo uma relação direta com os novos mercados e com as tendências e demandas que ainda não foram explorados de forma significativa - turismo, eventos, gastronomia, design e decoração, entre outras -, difundindo e ampliando saberes que revelem a riqueza de nossa diversidade cultural. Com o desenvolver das atividades, a associação identificou que precisava pensar algo além das peças que estava confeccionando. Então emergiu a proposta do Projeto "Chapecó Criativo: Narrativas Culturais", que busca a capacitação e o desenvolvimento de oficinas na área do artesanato cultural, incentivando a produção e a capacidade de oferecer ao mercado consumidor um artesanato dotado de valores culturais, estéticos e comerciais, que evidenciem aspectos regionais identitários.

Com essa nova proposta, o grupo também precisou ser alterado, pois o número de participantes proposto para essa etapa do projeto foi de 40 artesãos envolvidos diretamente. Todos residentes no município de Chapecó, prioritariamente chefes de família, mulheres em situação de vulnerabilidade social, grupos de inclusão produtiva informais, idosos que possam transmitir conhecimentos a seus descendentes, fazendo-se um resgate das tradições familiares, bem como artistas populares que estejam comprometidos em multiplicar técnicas e saberes ministrados nas oficinas.

Pensando no artesanato como fonte de renda e inclusão produtiva, seja do artesão individual ou pertencente à associação, o projeto visa orientar o artesão para que domine a gestão administrativo-financeira do seu negócio, desde a compra da matéria-prima até a formação do valor do seu produto. Considera-se o desenvolvimento do potencial humano, o que envolve conceitos do artesanato e a valorização da autoestima, além da inserção de elementos culturais e valores que permeiam o contexto cultural dos envolvidos.

Para atender ao mercado consumidor cada vez mais exigente, o projeto prevê a intervenção na área de diagnósticos, pesquisas, informações técnicas, aprimoramento no design e desenvolvimento de produtos através de oficinas criativas em formato de ateliê orientado. 
Também divulgação através de meios tecnológicos, material didático de apoio ao artesão para processos de capacitação, apoio à comercialização através de mostras e feiras, organização e coordenação de workshops para desenvolvimento de produtos.

García Canclini (1982) ressalta a relação do artesanato com o capitalismo ao explanar como os atributos inerentes ao artesanato se modificam sob a ótica e ação de um sistema capitalista e competitivo. $O$ autor também ressalta que o artesanato é obra das classes, grupos e núcleos não hegemônicos da sociedade e as camadas hegemônicas apreciam essas peças pelo seu exotismo, diferenciação, auferindo um ressignificado ao ambiente urbano, mais sofisticado, no campo da publicidade, no turismo, nos museus. Existe uma reelaboração de seu uso e consumo, sendo essa uma forma de o artesanato agregar mais valor.

Ainda, García Canclini (1982) expressa que, neste sistema capitalista e competitivo, a cultura hegemônica prevalece sobre a cultura popular, estimando o artesanato pelos aspectos estéticos das peças e ditando novas necessidades de consumo. Constitui-se uma nova ordem para o artesanato, baseada na forma de comercialização, configuração que reestrutura, remodela e reorganiza o significado e a função original do artesanato. $O$ consumidor e o comércio gradativamente irão transformar o poder de decisão da criação do artesão no poder de preferência do mercado, no que é comercializável, ao introduzir novas demandas e necessidades de renovação, assumindo um papel que anteriormente era exclusivo da manifestação cultural do artesão e do artesanato.

As artesãs localizadas no Distrito de Marechal Bormann Chapecó/SC demandam ações voltadas principalmente ao aproveitamento das vocações regionais e à preservação das culturas locais; assim, poderão ressaltar de forma significativa expressões culturais que narrem a história da região de Chapecó. Os artesãos ainda não possuem um guia iconográfico que referencie a identidade cultural local para nortear a confecção e comercialização do artesanato. Neste sentido, o trabalho em parceria com a universidade e pesquisa colabora para o fortalecimento e estabelecimento deste marco.

Neste contexto, destacamos o envolvimento do trabalho desenvolvido pela Associação Mães de Nazaré, que vem intensificando suas ações na busca pelos resultados com produtos qualificados, de amplo acesso cultural e que reforçam o caráter identitário de nossa gente. Pensar a respeito da importância do artesanato em Chapecó é trazer à tona uma crescente necessidade de ampliar as expressões culturais que narrem a história da população. $O$ artesanato traz essa premissa da valorização cultural, e isso somente ocorre de forma significativa e contundente quando se faz referência ao lugar de origem. Seja através dos saberes artesanais mais antigos, seja dos que surgem através de novos enredos, somente possuem essa carga simbólica quando retratam aquilo que os identifica.

Considerando a realidade das famílias que trabalham com o artesanato local, percebe-se que este está aliado ao aspecto social, econômico e cultural do ser humano, proporcionando emprego e renda, sendo um elo de desenvolvimento para esse grupo no ambiente onde residem. $O$ processo de trabalho das artesãs permite a liberdade de definir o ritmo de produção, a utilização de matéria-prima local, orientando formas de produzir e criar por meio do seu saber e cultura, com detalhes. Destaca-se a facilidade da sua organização familiar: na maioria, a atividade é praticada por mulheres, e advindas de um aprendizado tradicional, herança de nossos colonizadores. Além disso, o trabalho ora realizado permite a inclusão de artesãs no mercado e o desenvolvimento econômico local sustentável. 
O artesanato destaca-se por sua particularidade: permite inserir mais emprego, produção e consequente renda, em contraposição a uma menor necessidade e emprego de capital. Esta combinação pode promover gradativamente a melhoria da situação econômica e social dos artesãos em ambientes urbanos e rurais, com uma variedade de artefatos que podem ser comercializados nos mercados locais, nacionais e internacionais.

\section{Considerações finais}

Com este estudo, foi possível conhecer a dinâmica de organização da Associação Mães de Nazaré e participar da construção, formalização e organização dos seus produtos manuais, oriundos do artesanato, que se manifestam como importante fator cultural e de complemento de renda. A formalização do grupo em associação possibilitou a entrada de novas artesãs, divulgando e valorizando na comunidade o trabalho desenvolvido. A presença do trabalho da pesquisa e extensão da ITCP auxiliou na tomada de decisões em reuniões e na definição de planejamento e autogestão para a associação.

Ainda que o artesanato não seja a principal fonte de renda das artesãs, o reconhecimento do trabalho desenvolvido e da sua importância cultural, social e ambiental no município torna-se valor que não pode ser quantificável. Trata-se da valorização humana da arte, do sentimento de pertencimento e identidade do que se desenvolve, possibilitando o desenvolvimento de capacidades humanas e afetivas. Essas intervenções permitem o resgate de nossas memórias, narrativas e histórias, trazendo intrinsecamente uma requalificação do produto artesanal local, consolidando e promovendo a melhoria da condição de vida dos artesãos envolvidos, através da geração do trabalho e de renda.

Entende-se que oferecer uma maior orientação aos artesãos é importante para que ampliem seus mercados. Ações nesse sentido podem ser realizadas por meio de análises, pesquisas e informações técnicas; design e desenvolvimento de novos produtos; transferência de tecnologia e processos; testes e experimentações; habilitação e aperfeiçoamento dos recursos humanos; promoção, exposição, comercialização da produção (Barroso Neto, 2002). Estes produtos oriundos de nossa diversidade cultural e com "a cara de Chapecó" podem certamente representar de forma significativa o lugar de origem, aproveitando espaços que ainda não foram devidamente explorados, consolidando e promovendo o artesanato em Chapecó.

As ações e táticas oriundas de uma melhor gestão e organização para o artesanato podem alcançar diversos benefícios: uma melhor produção por meio do fortalecimento da cadeia produtiva, a divulgação e comercialização do artesanato envolvendo o marketing, a propaganda e a participação de feiras para enfrentar esse novo mercado consumidor, a inserção de princípios de qualidade e design por meio da capacitação local da comunidade.

\section{Referências bibliográficas}

Adams, T. (2014). Educação na economia solidária: desafios e perspectivas. Educação, 39(3) (UFSM).

Alves, H.F.I. (2004). Turismo e Desenvolvimento - a dimensão cultural. Santa Maria: PPGExR/UFSM. Dissertação de Mestrado). 
Barroso Neto, E. (2002). Curso design, identidade cultural e artesanato. Fortaleza: SEBRAE/FIEC, Módulos 1 e 2. Disponível em: http://www.eduardobarroso.com.br/design_artesanato.htm (acesso em: 10 jan. 2018).

Barros, M.L. de (1989). Memória e família. Estudos históricos, 2(3), 29-42. Rio de Janeiro. Disponível em: http://bibliotecadigital.fgv.br/ojs/index.php/reh/article/view/2277/1416 (acesso em: 28 mai. 2017).

Brandão, C.R. (1981). Pesquisa Participante. São Paulo: Brasiliense.

(2013). Prefácio. Em Steinberger, M. (Org.). Território, estado e políticas públicas espaciais (pp. 11-16). Brasília: Ler Editora.

Etges, V.E. (2001). A região no contexto da globalização: o caso do Vale do Rio Pardo. Em Vogt, O.; Silveira, R. Vale do Rio Pardo: (re) conhecendo a região. Santa Cruz do Sul: Edunisc.

(2005). Desenvolvimento regional sustentável: o território como paradigma. Redes, 10(3, set./dez.), 47-55. Santa Cruz do Sul.

Flores, M. (2017). A identidade cultural do território como base de estratégias de desenvolvimento: uma visão do estado da arte. 2006. Disponível em: http://indicadores.fecam.org.br/uploads/28/arquivos/4069_FLORES_M_Identidade_Territorial_como_Base_as_Estrategias_Desenvolvimento.pdf (acesso em: 21 mai. 2017).

Freire, P. (1986). Criando métodos de pesquisa alternativa: aprendendo a fazê-la melhor através da ação. Em Brandão, C.R. Pesquisa Participante. São Paulo: Brasiliense.

Froehlich, J.M. (2004). A (Re)construção de identidades e tradições - o rural como tema e cenário. In: Froehlich, J. M.; Diesel, V.(Orgs.). Espaço Rural e Desenvolvimento Regional. Ijuí: EDUNIJUí.

Gaiger, L. (Org.) (1996). Formas de resistência e de combate à pobreza. São Leopoldo: Unisinos.

García Canclini, N. (1982). As culturas populares no capitalismo. São Paulo: Brasiliense.

Halbwachs, M. (1990). Memória coletiva. São Paulo: Vértice.

Hall, S. (2002). A identidade cultural na pós-modernidade. 7. ed. Rio de Janeiro: DP\&A.

Ipea - Instituto de pesquisa econômica aplicada (2016). Os novos dados do mapeamento de economia solidária no Brasil: nota metodológica e análise das dimensões sócio estruturais dos empreendimentos. Brasília. Disponível em: http://repositorio.ipea.gov.br/bitstream/11058/7410/1/RP_Os\%20Novos\%20dados\%20 do\%20mapeamento\%20de\%20economia\%20solid\%C3\%A1ria\%20no\%20Brasil_2016.pdf (acesso em: 5 fev. 2018)

Lakatos, E.M.; Marconi, M. de A. (2001). Fundamentos de metodologia científica. 4. ed. rev. e ampl. São Paulo: Atlas.

Lima, R.G. (2003). Artesanato e arte popular: duas faces de uma mesma moeda? Rio de Janeiro: CNFCP. Disponível em: http://www.cnfcp.gov.br/pdf/Artesanato/Artesanato_e_Arte_Pop/CNFCP_Artesanato_Arte_Popular_Gomes_Lima.pdf (acesso em: 6 fev. 2018).

Long, N. (2007). Sociología del desarrollo: una perspectiva centrada en el actor. México: Centro de Investigaciones y Estudios Superiores en Antropología Social: El Colegio de San Luis.

Pecqueur, B. (2009). A guinada territorial da economía global. Política \& Sociedade - Revista de Sociologia Política, 8(14), 79-105. Florianópolis. Disponível em: https://periodicos.ufsc.br/index.php/politica/article/view/ 2175-7984.2009v8n14p79/10955 (acesso em: 03 jun. 2017).

Pollak, M.L. (1992). Memória e identidade social. Estudos teóricos, 5(10), 200-212. Rio de Janeiro.

Raffestin, C. (1993). Por uma geografia do poder. França. São Paulo: Ática.

Santos, M. (2009). A natureza do espaço: técnica e tempo. Razão e Emoção. São Paulo: Editora da Universidade de São Paulo.

Scheibe, K.E. (1985). Memória, identidade e história. Em Bassit, A.Z.; Ciampa, Â. da C.; Costa, M.R. (Coords.) (1985). Identidade: teoria e pesquisa. São Paulo: EDUC. 
Simson, O.R. de M. von (2000). Memória, Em Faria Filho, L.M. (Org.). Arquivos, fontes e novas tecnologias: questões para história da educação (pp. 63-74). São Paulo: Editora Autores Associados.

Tonneau, J.P. (2002). Articulação entre as escolas territoriais e consequências sobre o planejamento rural. Em Sabourin e Teixeira (Org.). Planejamento e desenvolvimento dos territórios rurais (pp. 219-232). Brasília, DF: Embrapa.

Unochapecó (2005). Resolução n 98/CONSUN. Chapecó. 